\title{
Advancing rural food access policy research priorities: Process and potential of a transdisciplinary working group
}

\author{
Rural Food Access Working Group \\ Sheila Fleischhacker, ${ }^{a} *$ National Institutes of Health \\ Donna Johnson, ${ }^{\mathrm{b}}$ University of Washington \\ Emilee Quinn, ${ }^{\mathrm{c}}$ University of Washington \\ Stephanie B. Jilcott Pitts, ${ }^{\mathrm{d}}$ East Carolina University \\ Carmen Byker, ${ }^{\mathrm{e}}$ Montana State University \\ Joseph R. Sharkey, ${ }^{\mathrm{f}}$ Texas A\&M University Health Science Center
}

Submitted August 19, 2013 / Revised September 17, 2013 / Published online September 19, 2013

Citation: Fleischhacker, S., Johnson, D., Quinn, E., Jilcott Pitts, S. B., Byker, C., \& Sharkey, J. R. (2013).

Advancing rural food access policy research priorities: Process and potential of a transdisciplinary

working group. Journal of Agriculture, Food Systems, and Community Development, 3(4), 201-212.

http://dx.doi.org/10.5304/jafscd.2013.034.027

Copyright (C) 2013 by New Leaf Associates, Inc.

\begin{abstract}
Residents of rural communities currently face disproportionately higher risk for nutrition-related chronic diseases compared to residents of urban communities. Rural residents also face disparities

a* Corresponding author: Sheila Fleischhacker, PhD, JD, Senior Public Health and Science Policy Advisor, NIH Division of Nutrition Research Coordination, National Institutes of Health, Department of Health and Human Services; Two Democracy Plaza, Room 635; 6707 Democracy Boulevard MSC 5461; Bethesda, Maryland 20892-5461 USA; +1-301594-7440; sheila.fleischhacker@,nih.gov

b Donna Johnson, PhD, RD, Associate Director, Center for Public Health Nutrition; Associate Professor, Nutrition Sciences; University of Washington School of Public Health; Interdisciplinary Program in Nutritional Sciences.

${ }^{c}$ Emilee Quinn, MPH, Research Coordinator, Center for Public Health Nutrition; University of Washington.

and unique barriers in accessing healthy, affordable foods. In 2011, participants of the Centers for Disease Control and Prevention (CDC)-funded

\footnotetext{
d Stephanie B. Jilcott Pitts, PhD, Assistant Professor, Public Health; East Carolina University; Brody School of Medicine; Department of Public Health.

e Carmen Byker, Assistant Professor, Food and Nutrition and Sustainable Food Systems; Montana State University.

${ }^{\mathrm{f}}$ Joseph R. Sharkey, PhD, MPH, RD, Director, Program for Research and Outreach-Engagement on Nutrition and Health Disparities; Professor, Health Promotion and Community Health Sciences; School of Rural Public Health, Texas A\&M University Health Science Center.

Note: This article was supported through NOPREN by Cooperative Agreement Number 5U48-DP001911 from the CDC. The content is solely the responsibility of the authors and does not necessarily represent the official views of the
} CDC, National Institutes of Health (NIH), or RWJF.
\end{abstract}


Nutrition and Obesity Policy Research and Evaluation Network (NOPREN) formed the Rural Food Access Working Group (RFAWG). Since then, the RFAWG has been focusing on conducting collaborative transdisciplinary research that includes a concept mapping project that identified and prioritized policy research ideas perceived as important to improving access to healthy, affordable foods in rural communities. This commentary reflects on the process and potential of this emergent transdisciplinary RFAWG to advance rural food access policy research priorities, sharing how after nearly two years of convening, RFAWG has identified and started to address various rural food access policy research needs and opportunities that the group has deemed important for the near and longterm. The research priorities and process taken thus far by RFAWG reflect the participants' own work, institutional and geographic strengths, and negotiated approaches to collaborating with the transdisciplinary team using pooled but often limited resources. The group has benefited from the involvement of a variety of experts skilled in various disciplines and research methodologies touching the food system. RFAWG continues to strategize methods to advance rural food access policy research priorities through transdisciplinary team efforts, innovative partnerships, rigorously designed research processes, and contextually crafted dissemination and translation approaches.

\section{Keywords}

community development, food access, food systems, policy research, public health, rural

\section{Introduction}

Eliminating health disparities among rural communities is a Healthy People $2020^{1}$ objective, because rural adults and youth in the United States currently face disproportionately higher risk for nutrition-related chronic diseases when compared to urban residents (Krishna, Gillespie, \& McBride, 2010). Indeed, the obesity prevalence rate was 39.6 percent of rural adults compared to 33.4 percent of urban adults, and remained significantly higher even after controlling for demographic, diet, and

\footnotetext{
${ }^{1}$ http://www.healthypeople.gov/2020
}

physical activity (Befort, Nazir, \& Perri, 2012). Even for children, living in rural versus metropolitan areas was associated with being overweight or obese (Lutfiyya, Lipsky, Wisdom-Behounek, \& Inpanbutr-Martinkus, 2007). Increasing the consumption of healthier foods such as fruits and vegetables among rural residents may help reduce these disparities (Carter, Gray, Troughton, Khunti, \& Davies, 2010). A recent study reported that rural adults were less likely than their urban counterparts to consume five or more daily servings of fruits and vegetables; the study investigators discussed how these dietary differences may explain in part differences in chronic disease risk (Lutfiyya, Chang, \& Lipsky, 2012). This study, among others, identified the unique barriers rural residents must overcome to access a range of healthy, affordable foods, including living near relatively few grocery stores and produce markets (Bailey, 2010; Blanchard \& Matthews, 2008; Kaufman, 1999; Sharkey, Dean, Nalty, \& Xu, 2013). Equally problematic, the few food retailers located in rural communities tend to offer fewer and often more expensive healthier options (Liese, Weis, Pluto, Smith, \& Lawson, 2007; O'Connell, Buchwald, \& Duncan, 2011). Not surprisingly, a number of studies find rural residents overcome significant transportation hurdles to access healthy, affordable foods, including longer, more expensive commutes, and higher transportation costs (Dean \& Sharkey, 2011; Jilcott, Moore, Wall-Bassett, Liu, \& Saelens, 2011; Sharkey, Horel, Han, \& Huber, 2009; Smith \& Morton, 2009; Yousefian, Leighton, Fox, \& Hartley, 2011). Research also commonly characterizes rural food environments as complex systems encompassing a variety of traditional and nontraditional sources, including but not limited to retail food outlets; farm-to-consumer outlets; mass merchandisers; flea markets; fast-food restaurants and/or convenience stores nested within gas stations; gardening; hunting; and reliance on neighbors (Dean, Sharkey, \& St. John, 2011; Sharkey, Dean, \& Johnson, 2012; Sharkey, Johnson, Dean, \& Horel, 2011; Valdez, Dean, \& Sharkey, 2012; Van Hoesen, Bunkley, \& Currier, 2013; Wegener \& Hanning, 2010; Yousefian et al., 2011).

Multidisciplinary experts have recently explored how food system policies in both rural 
and urban communities can promote health and reduce nutrition-related chronic diseases (Hamm, 2008, 2009; Muller, Tagtow, Roberts, \& MacDougall, 2009; Story, Hamm, \& Wallinga, 2009). As one example, attracting or enhancing healthy food retail options in rural communities is a promising strategy to facilitate improved access to nutritious, affordable foods (Brennan, Castro, Brownson, Claus, \& Orleans, 2011; Story, Kaphingst, Robinson-O’Brien, \& Glanz, 2008). But the evidence supporting local, state, tribal, and national initiatives utilizing public-private partnerships to open or renovate retail food outlets in underserved communities predominantly originates from research conducted in urban communities (Barnidge, Radvanyi, Duggan, Motton, Wiggs, Baker, \& Brownson, 2013; Fleischhacker, Flournoy, \& Moore, 2012). Limited research has been conducted on food access opportunities and obstacles in rural communities or with rural residents. Research finds that what may work in urban communities may not be perceived as feasible or effective by rural residents (Jilcott Pitts, Whetstone, Wilkerson, Smith, \& Ammerman, 2012; Pitts, Smith, Thayer, Drobka, Miller, Keyserling, \& Ammerman, 2013). Moreover, efforts limited to adopting what works in urban communities to rural communities hinders developing innovative policy strategies tailored specifically to maximizing the unique assets of rural communities.

To identify knowledge gaps and policy research needs that have the greatest potential for improving access to healthy, affordable foods in rural communities, a need exists for transdisciplinary research teams composed of experts from a range of disciplines (Story et al., 2009). The aim of this commentary is to reflect on the process and potential of an emergent transdisciplinary rural food access working group to identify and advance rural food access policy research priorities.

\section{Nutrition and Obesity Policy Research and Evaluation Network (NOPREN)} NOPREN $^{2}$ is a thematic research network of the U.S. Centers for Disease Control and Prevention (CDC)'s Prevention Research Centers (PRCs)

\footnotetext{
2 http://www.nopren.org/
}

program. ${ }^{3}$ PRCs conduct prevention research with underserved communities, through a network of 37 academic research centers associated with U.S. schools of public health or medicine (Greenlund \& Giles, 2012). Known as leaders in communitybased participatory research, PRCs form long-term collaborations to promote health and reduce chronic diseases with a variety of partners, such as community members and organizations; local, state, and tribal health departments; educational boards; and the private sector. Created in 2009 by CDC's Division of Nutrition, Physical Activity and Obesity (DNPAO) ${ }^{4}$ NOPREN participants conduct transdisciplinary nutrition- and obesityrelated policy research and evaluation along a policy change continuum (see figure 1) (Blanck \& Kim, 2012). Since its inception, NOPREN has evaluated policies and processes for promoting healthy eating in a variety of settings at the local Johnson, Payne, McNeese, \& Allen, 2012; Sharkey, Dean, \& Nalty, 2012; Ulmer, Rathert, \& Rose, 2012), state (Cradock, Wiking, Olliges, \& Gortmaker, 2012), tribal (Fleischhacker, Byrd, Ramachandran, Vu, Ries, Bell, \& Evenson, 2012), and federal levels (Cradock et al., 2012; Giles, Kenney, Gortmaker, Lee, Thayer, Mont-Ferguson, \& Cradock, 2012).

The Harvard School of Public Health Prevention Research Center ${ }^{5}$ coordinates network activities that include facilitating the growth and development of four research working groups:

(1) food policy councils, (2) policy communication, (3) rural food access, and (4) water access. Each working group identifies meaningful and feasible focus areas to advance the state of the science, while continually leveraging expertise, funding, and resources across the network. For the last three years, NOPREN participants have met in person just prior to the start of the annual grantee meeting of Healthy Eating Research (HER), ${ }^{6}$ a national program of the Robert Wood Johnson Foundation (RWJF). ${ }^{7}$ HER invited NOPREN participants to

\footnotetext{
${ }^{3}$ http://www.cdc.gov/prc/

${ }^{4}$ http://www.cdc.gov/nccdphp/dnpao/index.html

${ }^{5}$ http://www.hsph.harvard.edu/prc/

${ }^{6}$ http://www.healthyeatingresearch.org/

${ }^{7}$ http://www.rwjf.org/
} 
Figure 1. Nutrition and Obesity Policy Research and Evaluation Network's (NOPREN) Policy Continuum

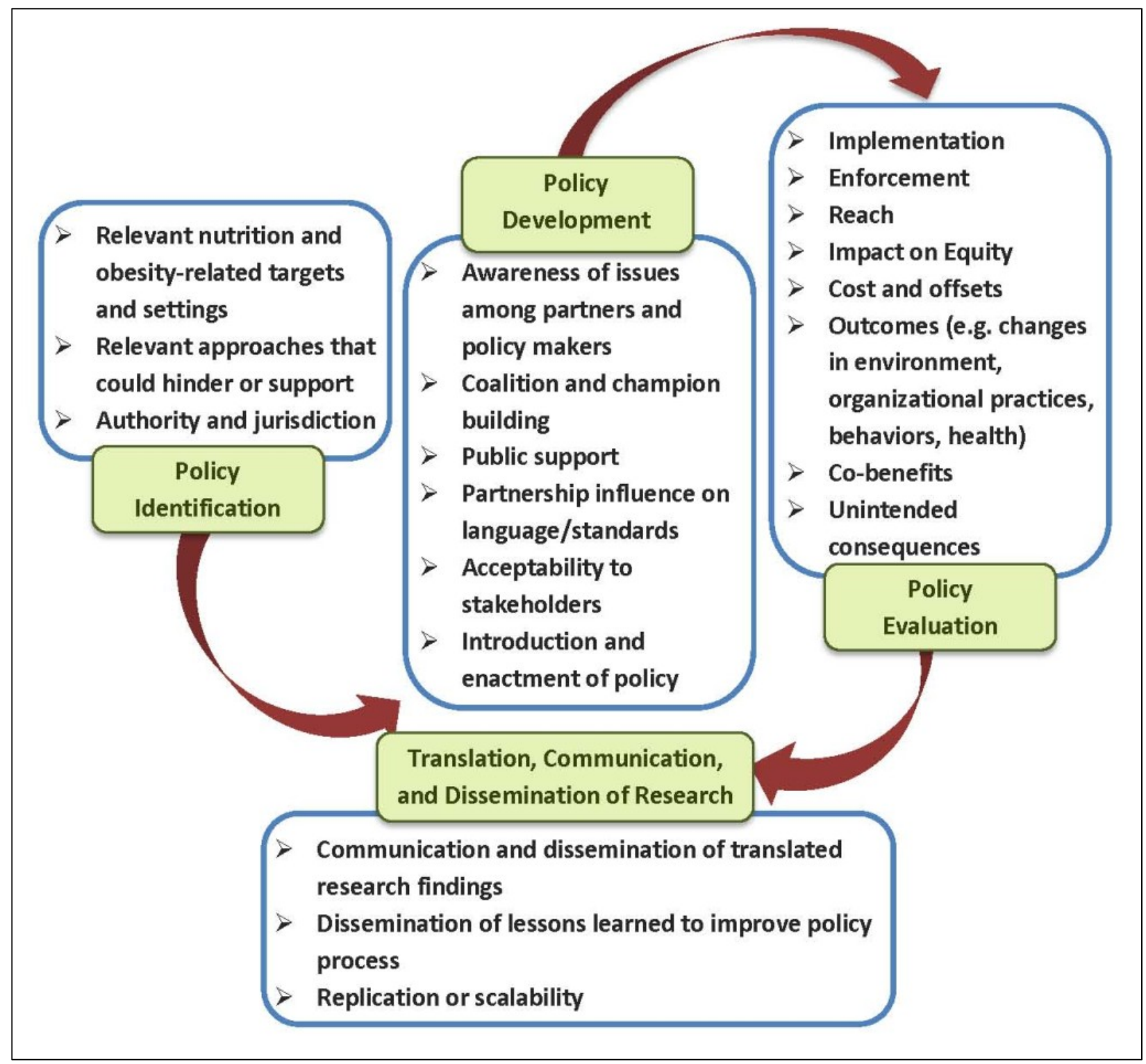

Adopted with permission from Blanck, H., \& Kim, S. (2012). Creating supportive nutrition environments for population health impact and health equity: An overview of the Nutrition and Obesity Policy Research and Evaluation Network's Efforts. American Journal of Preventive Medicine, 43(3 Supplement 2), S85-S90.

attend their annual meeting, provided technical assistance with workshop planning and preparation, and collaborated with NOPREN to help make their three in-person meetings possible. HER also collaborates with NOPREN among other organizations on an Early Care and Education Working Group.
NOPREN Rural Food Access Working Group (RFAWG)

This commentary focuses on the process and potential of RFAWG, which emerged in February 2011 as an official working group during NOPREN's first annual meeting in Austin, Texas. Under the leadership of Co-Chairs Donna Johnson, $\mathrm{PhD}, \mathrm{RD}$, of the University of 
Washington and Joseph Sharkey, PhD, MPH, RD, of Texas A\&M University, RFAWG participants focus on:

- Identifying and prioritizing key constructs and determinants related to rural food access;

- Sharing and shaping common methods and metrics for understanding constructs and determinants related to rural food access, including exploring how best to define rural communities;

- Strategizing ways to conduct and fund transdisciplinary rural food access research at and between NOPREN-funded PRCs, NOPREN affiliates, and other key stakeholder institutions, agencies, and organizations; and

- Advancing the role of policy identification, development, implementation, and evaluation related to understanding and increasing access to healthy foods in rural communities.

RFAWG convenes its members through monthly calls on which participants work on group aims, seek feedback and guidance from one another on projects, share relevant developments and resources, and move forward on collective initiatives. Often during calls the working group coordinator facilitates presentations from RFAWG participants, research colleagues, or relevant stakeholders. These presentations have focused on specific research and evaluation studies, the applications of particular research methods, and theoretical and methodological issues regarding conceptualizing rural neighborhoods for research purposes. Occasionally, presentations elaborate on funding and policy developments or allow for exploring collaborations with other groups. In addition, the RFAWG coordinator disseminates monthly, or as needed time-sensitive, emails to coordinate group work or share relevant resources.

\section{RFAWG Participant Expertise}

RFAWG benefits from a breadth and depth of participant expertise relevant to rural food systems and health. The group includes more than two dozen participants from diverse geographic regions across the U.S., approximately 15 of whom are active contributors. During June 2013, RFAWG conducted a brief online survey of participants $(n=13)$ to document their areas of expertise and policy research foci related to rural access to healthy food. Based on the results of this survey, the majority of RFAWG participants self-identified as public health nutrition researchers. Several reported additional training and expertise in agricultural production, applied economics, linguistics, medical and rural sociology, multiculturalism, and public health law and policy. Participants also reported collaborating with partners from these same disciplines, as well as with those in the community development, medicine, physical activity, sociology, public policy, and regional and urban planning fields.

RFAWG participants study and evaluate programs and practices that promote or hinder healthy eating, and associated outcomes, across all policy levels and in a range of rural communities across the U.S. That is, RFAWG participants work in small towns, areas of low population density, various agricultural communities, and American Indian and Alaska Native communities. Target populations predominantly focus on at-risk groups such as low-income, racial and ethnic minorities, and immigrants. The age groups range from youth to seniors, including specific efforts to work with women of reproductive age.

Table 1 illustrates how RFAWG policy research most often targets and creates long-term partnerships with community coalitions, child-care centers, schools, worksites, community spaces and places, retail food outlets, federal food and nutrition assistance programs, and local and state public health departments. The majority of RFAWG participants examine state and local policies. For example, participants have examined processes and outcomes associated with statewide food systems, state-level and statewide initiatives such as the CDC-funded state Nutrition, Physical Activity and Obesity grants and local Community Transformation Grants, and state policies such as school nutrition standards, as well as local and county-level initiatives such as the CDC's Racial and Ethnic Approaches to Community Health 
Table 1. Programs, Systems, and Initiatives Addressed Through Rural Food Access Working Group (RFAWG) Participants' Policy Research (listed in order from most to least common)

\begin{tabular}{|c|c|}
\hline Program, Systems, or Initiative Category & Examples of RFAWG Participants' Policy Research \\
\hline Local food distribution & $\begin{array}{l}\text { - Establishing a rural farmers' market } \\
\text { - Evaluating a school farm-to-school procurement policy }\end{array}$ \\
\hline $\begin{array}{l}\text { Federal food and nutrition assistance } \\
\text { programs }\end{array}$ & $\begin{array}{l}\text { - Evaluating a U.S. Department of Agriculture Special Supplement } \\
\text { Nutrition Program for Women, Infants, and Children (WIC) "produce } \\
\text { bundle" project } \\
\text { - Evaluating the expansion of the U.S. Department of Agriculture } \\
\text { Summer Food Service Program (SFSP) for children in nontraditional } \\
\text { locations }\end{array}$ \\
\hline Schools & $\begin{array}{l}\text { - Evaluating the provision of summer meals in schools } \\
\text { - Measuring plate waste in school meals }\end{array}$ \\
\hline Rural food retail systems & $\begin{array}{l}\text { - Evaluating a collaborative community-academic mobile market project } \\
\text { for low-income seniors } \\
\text { - Evaluating rural Healthy Corner Stores' development and } \\
\text { implementation }\end{array}$ \\
\hline Population-based prevention & $\begin{array}{l}\text { - Supporting and conducting CDC Communities Putting Prevention to } \\
\text { Work (CPPW) project evaluations in partnership with state and local } \\
\text { health departments } \\
\text { - Supporting and conducting CDC Racial and Ethnic Approaches to } \\
\text { Community Health (REACH) initiative evaluations in partnership with } \\
\text { community coalitions }\end{array}$ \\
\hline Rural food production & - Examining tribal implementation of community gardens \\
\hline Child care & - Surveying child care providers' nutrition policies \\
\hline Rural economic development & $\begin{array}{l}\text { - Conducting economic development and asset mapping assessments } \\
\text { with tribal communities } \\
\text { - Studying the impact of food systems on farmer revenue }\end{array}$ \\
\hline $\begin{array}{l}\text { Rural food system building and } \\
\text { infrastructure }\end{array}$ & $\begin{array}{l}\text { - Disseminating model food hub interventions } \\
\text { (http://www.centertrt.org) }\end{array}$ \\
\hline Other & $\begin{array}{l}\text { - Studying the impact of labeling information on consumer decisions } \\
\text { - Studying transportation access to healthy food } \\
\text { - Examining emergency food access (e.g., food banks) }\end{array}$ \\
\hline
\end{tabular}

(REACH) initiative. Participants have also conducted policy research at the national level (e.g., national evaluation of CDC programs), within institutions (e.g., after-school programs), and within American Indian tribes (e.g., tribal policy assessments). Only one RFAWG participant reported focusing on rural policies outside the U.S.

Another strength of RFAWG is the breadth and depth of expertise that participants provide on methodologies and metrics for researching and evaluating policies and processes. The vast majority, as indicated in our 2013 survey, measure and describe the food environment in their work, and a significant majority measure and describe health outcomes, study interventions, and/or conduct community-based participatory research. Some participants conduct epidemiological, systems, or policy process research, develop methods, or conduct policy analyses. Table 1 provides examples of the types of policy research conducted by RFAWG participants across a range of programs, systems, and initiatives, while table 2 illustrates the ways in which RFAWG participants engage in such work across the NOPREN policy research continuum presented in figure 1. 
Table 2. Rural Food Access Working Group (RFAWG) Policy Research Across the Nutrition and Obesity Policy Research and Evaluation Network (NOPREN) Policy Continuum

\begin{tabular}{|c|c|}
\hline NOPREN Policy Continuum Category & Examples of RFAWG Participants' Policy Research \\
\hline $\begin{array}{l}\text { Policy Identification: Identify relevant rural } \\
\text { food system policies }\end{array}$ & $\begin{array}{l}\text { - Community audits and needs assessments } \\
\text { - } \text { - Interviews with rural store owners } \\
\text { - Key informant interviews and informal meetings with local leaders } \\
\text { - Policy scans } \\
\text { - Feasibility and impact analyses } \\
\text { - Spatial food access mapping } \\
\text { - Development and use of CDC's Common Community Measures for } \\
\text { Obesity (COCOMO) in rural settings to identify “winnable" policies } \\
\text { (Jilcott Pitts et al., 2012) }\end{array}$ \\
\hline $\begin{array}{l}\text { Policy Development: Understand the policy } \\
\text { development process as it affects rural food } \\
\text { access }\end{array}$ & $\begin{array}{l}\text { - Studies of decision-maker perceptions regarding policy options } \\
\text { - Case studies and social network analyses pertaining to community } \\
\text { coalition efforts to develop and implement policies } \\
\text { - Systematic reviews of literature }\end{array}$ \\
\hline $\begin{array}{l}\text { Translation and Dissemination: Translate and } \\
\text { disseminate rural food policy research }\end{array}$ & $\begin{array}{l}\text { - Peer-reviewed manuscripts and conference posters and presentations } \\
\text { - Policy briefs and evaluation summaries } \\
\text { - Compilations of "success stories" and “lessons learned" } \\
\text { - Outreach publications and presentations } \\
\text { - Development of toolkits } \\
\text { - Web content and social media (e.g., Twitter) } \\
\text { - University of North Carolina Center for Health Promotion and Disease } \\
\text { Prevention Center for Training and Research Translation (Center TRT) }\end{array}$ \\
\hline $\begin{array}{l}\text { Policy Evaluation: Evaluate rural food system } \\
\text { policies }\end{array}$ & $\begin{array}{l}\text { - Evaluation of public health outcomes including changes in food } \\
\text { environments, access to healthy foods, food consumption, and food } \\
\text { security } \\
\text { - Evaluation of food system outcomes, such as changes in practices } \\
\text { and policies, and economic viability of interventions (e.g., mobile } \\
\text { markets) } \\
\text { - Documentation of unintended policy consequences }\end{array}$ \\
\hline
\end{tabular}

${ }^{a}$ http://www.centertrt.org

\section{RFAWG Collaborative Process}

Besides work conducted at individual research institutions and sites, RFAWG participants collaborate in several ways to advance the study of policies at the intersection of public health and food systems among rural communities. One of the first group undertakings that the majority of RFAWG participants collaborated on was to identify the most salient topics to include in RFAWG's policy research agenda. Conducting a process similar to that of NOPREN's "sister" network, Physical Activity Policy Research Network (PAPRN) (Brownson et al., 2008) and using concept mapping methodology (Kane \& Trochim, 2007), RFAWG researchers collected insights from approximately 200 rural food access "experts" throughout the U.S. on important policy research issues to improving rural food access. Through a combination of concept-mapping methodologies and consensus-building, several RFAWG participants gathered in person in September 2012 and continue to work together on a manuscript via email and conference calls to identify and prioritize high-level policy research priorities based on the insights gleaned from the 200 experts. At this stage, key policy research priorities deemed important and feasible to focus on include food and nutrition assistance program adoptions for rural populations; retail availability and shopping patterns in rural communities; food 
production capacity; and economic development and customer purchasing power associated with food enterprises.

Two additional subgroups of RFAWG have emerged to advance the state of the science for measuring and improving access to healthy food in rural communities, both starting with systematic reviews of relevant topics. The first literature review that emerged from RFAWG and was funded in part through HER examined the evidence for validity reported for secondary retail food outlet data sources for characterizing retail food environments (Fleischhacker, Evenson, Sharkey, Pitts, \& Rodriguez, 2013). The review found methods used and evidence for validity reported varied by the secondary data sources examined, primary data gathering approaches, retail food outlets examined, and geographic and sociodemographic characteristics, and it discussed how limited evidence for validity was reported in rural settings in comparison to urban settings. The second systematic review aims to inform revisions to the Common Community Measures for Obesity Prevention (COCOMO) (Khan, Sobush, Keener, Goodman, Lowry, Kakietek, \& Zaro, 2009) for greater applicability to rural areas, since findings from a CDC Communities Putting Prevention to Work (CPPW) project reported rural stakeholders' diverging perceptions on the feasibility of COCOMO strategies in their communities (Jilcott Pitts et al., 2012). This divergence related to rural culture, infrastructure, extent of leadership support, and likely funding support. The University of North Carolina at Chapel Hill in partnership with East Carolina University is leading this review that involves collecting and coding obesity-prevention strategies developed, implemented, and/or evaluated in rural communities. The co-principal investigatorss of this project are both RFAWG participants and solicited the help of RFAWG colleagues to identify relevant peer-reviewed publications and resources, as well as to serve as reviewers in their abstracting process of included literature.

\section{Lessons Learned \& Future Directions}

RFAWG formed in response to knowledge gaps and an urgent need for improving access to healthy foods in rural communities, and recognized that a critical ingredient to advancing the state of the science for rural food access policy research was assembling transdisciplinary efforts. After nearly two years of convening and collaborative projects, RFAWG has identified and started to address various rural food access policy research needs and opportunities the group has deemed important for the near and long term. Collaborative efforts have allowed RFAWG participants to leverage one anothers' expertise and perspective with a greater range of rural communities, allowing for comparing and contrasting of similarities and differences across often smaller community study samples. The group has also benefitted from the involvement of a variety of experts skilled in various disciplines and research methodologies touching the food system. The research priorities and process taken thus far by RFAWG reflect the participants' own work, institutional and geographic strengths, and negotiated approaches to collaborating with the transdisciplinary team using pooled but often limited resources.

Based on RFAWG discussions and conceptmap study preliminary findings, RFAWG has gained insight into a range of research questions pertaining to the intersection of public health and food systems in rural communities. Many of these questions relate to better understanding the connections between aspects of the food system (e.g., production, processing, and distribution) and consumer access - and specifically to questions of costs, benefits, economic viability, and shared benefits across stakeholder groups (e.g., producers, rural residents, and consumers). As one example, several RFAWG participants recently formed the "RFAWG Local Economies" subgroup to focus on a particular finding of the concept-mapping study illuminating the relationship between community economic development — including the viability of food enterprises - and access to healthy foods in rural, agricultural communities. Part of their process involves reviewing the literature on impacts of direct marketing on rural economies.

RFAWG participants have also identified other areas of interest, including the need for developing accurate and consistent health metrics in evalua- 
tions of food system and community development initiatives, as well as innovative ways to include economic and food systems metrics in public health nutrition initiatives. Equally as important, RFAWG recognizes a particular, tailored need to disseminate evidence and tools to build researchers and practitioners' capacity to adapt, implement, and evaluate improvements to rural food systems. Put another way, researchers and practitioners need valid and reliable tools and access to information on "what works" in rural food systems. As one example, the University of North Carolina at Chapel Hill Center for Training and Research Translation $^{8}$ disseminates obesity prevention evidence nationwide, and this type of web-based approach may facilitate the dissemination of strategies particular to rural food access.

As a group, RFAWG continues to strategize methods to advance rural food access policy research priorities through transdisciplinary team efforts, innovative partnerships, rigorously designed research processes, and contextually crafted dissemination and translation approaches.

\section{Acknowledgments}

We appreciate the feedback from Rural Food Access Working Group (RFAWG) participants on this commentary, including Ellen Barnidge, Wesley Dean, Jennifer Leeman, Jane Kolodinsky, Emily Piltch, and Marilyn Sitaker. Other RFAWG participants' input has been invaluable towards shaping our policy research priorities and process including that from Alice Ammerman, Courtney Pinard, and Rebecca Seguin. In addition, we appreciate the support from Angie Cradock and Steve Gortmaker through the Nutrition and Obesity Policy Research and Evaluation Network (NOPREN); Heidi Blanck, Sonia Kim, and Demia Wright, from the U.S. Centers for Disease Control and Prevention (CDC); and Mary Story and Karen Kaphingst, from Healthy Eating Research (HER), a national program of the Robert Wood Johnson Foundation (RWJF).

\footnotetext{
${ }^{8}$ http://www.centertrt.org
}

\section{References}

Bailey, J. (2010). Rural grocery stores: Importance and challenges. Retrieved from the Center for Rural Affairs website: http://files.cfra.org/pdf/ruralgrocery-stores.pdf

Barnidge, E. K., Radvanyi, C., Duggan, K., Motton, F., Wiggs, I., Baker, E. A., \& Brownson, R. C. (2013). Understanding and addressing barriers to implementation of environmental and policy interventions to support physical activity and healthy eating in rural communities. Journal of Rural Health, 29(1), 97-105. http://dx.doi.org/10.1111/ j.1748-0361.2012.00431.x

Befort, C. A., Nazir, N., \& Perri, M. G. (2012). Prevalence of obesity among adults from rural and urban areas of the United States: Findings from NHANES (2005-2008). Journal of Rural Health, 28(4), 392-397. http://dx.doi.org/10.1111/j.17480361.2012.00411.x

Blanchard, T. C., \& Matthews, T. L. (2008). Retail concentration, food deserts, and fooddisadvantaged communities in rural America. In C. C. Hinrichs \& T. A. Lyson (Eds.), Remaking the North American food system: Strategies for sustainability (pp. 201-215. Lincoln, Nebraska: University of Nebraska Press.

Blanck, H. M., \& Kim, S. A. (2012). Creating supportive nutrition environments for population health impact and health equity: An overview of the Nutrition and Obesity Policy Research and Evaluation Network's efforts. American Journal of Preventive Medicine, 43(3, Supplement 2), S85-S90. http://dx.doi.org/10.1016/j.amepre.2012.06.005

Brennan, L., Castro, S., Brownson, R. C., Claus, J., \& Orleans, C. T. (2011). Accelerating evidence reviews and broadening evidence standards to identify effective, promising, and emerging policy and environmental strategies for prevention of childhood obesity. Annual Review of Public Health 32, 199-223. http://dx.doi.org/10.1146/annurevpublhealth-031210-101206

Brownson, R. C., Kelly, C. M., Eyler, A. A., Carnoske, C., Grost, L., Handy, S. L.,...Schmid, T. L. (2008). Environmental and policy approaches for promoting physical activity in the United States: A research agenda. Journal of Physical Activity and Health, 5(4), 488-503. 
Carter, P., Gray, L. J., Troughton, J., Khunti, K., \& Davies, M. J. (2010). Fruit and vegetable intake and incidence of type 2 diabetes mellitus: Systematic review and meta-analysis. British Medical Journal, 341, c4229. http://dx.doi.org/10.1136/bmj.c4229

Cradock, A. L., Wiking, C. L., Olliges, S. A., \& Gortmaker, S. L. (2012). Getting back on tap: The policy context and cost of ensuring access to lowcost drinking water in Massachusetts schools. American Journal of Preventive Medicine, 43(3 Suppl 2), S95-S101.

http://dx.doi.org/10.1016/j.amepre.2012.05.016

Dean, W. R., \& Sharkey, J. R. (2011). Rural and urban differences in the associations between characteristics of the community food environment and fruit and vegetable intake. Journal of Nutrition Education and Behavior, 43(6), 426-433. http://dx.doi.org/10.1016/j.jneb.2010.07.001

Dean, W. R., Sharkey, J. R., \& St. John, J. (2011). Pulga (flea market) contributions to the retail food environment of colonias in the South Texas border region. Journal of the Academy of Nutrition and Dietetics, 111(5), 705-710.

http://dx.doi.org/10.1016/j.jada.2011.02.009

Fleischhacker, S., Byrd, R. R., Ramachandran, G., Vu, M., Ries, A., Bell, R. A., \& Evenson, K. R. (2012). Tools for healthy tribes: Improving access to healthy foods in Indian Country. American Journal of Preventive Medicine, 43 (3 Supplement 2), S123-S129. http://dx.doi.org/10.1016/j.amepre.2012.05.015

Fleischhacker, S. E., Evenson, K. R., Sharkey, J., Jilcott Pitts, S. B., \& Rodriguez, D. A. (2013). Validity of secondary retail food outlet data: A systematic review. American Journal of Preventive Medicine, 45(4), 462-473.

http://dx.doi.org/10.1016/j.amepre.2013.06.009

Fleischhacker, S. E., Flournoy, R., \& Moore, L. V. (2012). Meaningful, measurable, and manageable approaches to evaulating healthy food financing intiatives: An overview of resources and approaches. Journal of Public Health Management and Practice. Advance online publication. http://dx.doi. org/10.1097/PHH.0b013e318271c6eb

Giles, C. M., Kenney, E. L., Gortmaker, S. L., Lee, R. M., Thayer, J. C., Mont-Ferguson, H., \& Cradock, A. L. (2012). Increasing water availability during afterschool snack: Evidence, strategies, and partnerships from a group randomized trial. American Journal of Preventive Medicine, $43(3$

Supplement 2), S136-S142. http://dx.doi.org/10.1016/j.amepre.2012.05.013

Greenlund, K. J., \& Giles, W. H. (2012). The Prevention Research Centers Program: Translating research into public health practice and impact. American Journal of Preventive Medicine, 43 (3 Supplement 2), S91-S92.

http://dx.doi.org/10.1016/j.amepre.2012.06.002

Hamm, M. W. (2008). Linking sustainable agriculture and public health: Opportunities for realizing multiple goals. Journal of Hunger and Environmental Nutrition, 3(2-3), 169-185. http://dx.doi.org/10.1080/19320240802243241

Hamm, M. W. (2009). Principles for framing a healthy food system. Journal of Hunger and Environmental Nutrition, 4(3-4), 241-250. http://dx.doi.org/10.1080/19320240903321219

Jilcott, S. B., Moore, J. B., Wall-Bassett, E. D., Liu, H., \& Saelens, B. E. (2011). Association between travel times and food procurement practices among female Supplemental Nutrition Assistance Program participants in eastern North Carolina. Journal of Nutrition Education and Behavior, 43(5), 385-389. http://dx.doi.org/10.1016/j.jneb.2010.11.004

Jilcott Pitts, S. B., Whetstone, L., Wilkerson, J., Smith, T., \& Ammerman, A. (2012). A community-driven approach to identifying "winnable" policies using the Centers for Disease Control and Prevention's Common Community Measures for Obesity Prevention. Preventing Chronic Disease: Public Health Research, Practice, and Policy, 9, E79. http://dx.doi.org/10.5888/pcd9.110195

Johnson, D. B., Payne, E. C., McNeese, M. A., \& Allen, D. (2012). Menu-labeling policy in King County, Washington. American Journal of Preventive Medicine, 43(3 Supplement 2), S130-S135. http://dx.doi.org/10.1016/j.amepre.2012.05.014

Kane, M., \& Trochim, W. M. K. (2007). Concept mapping for planning and evaluation. Thousand Oaks, California: SAGE Publications.

Kaufman, P. R. (1999). Rural poor have less access to supermarkets, large grocery stores. Rural Development Perspectives, 13(3), 19-26. 
Khan, L. K., Sobush, K., Keener, D., Goodman, K., Lowry, A., Kakietek, J., \& Zaro, S. (2009). Recommended community strategies and measurements to prevent obesity in the United States. Morbidity and Mortality Weekly Report Recommendations and Reports, 58(RR-07), 1-26.

Retrieved from http://www.cdc.gov/mmwr/indrr_2009.html

Krishna, S., Gillespie, K. N., \& McBride, T. M. (2010). Diabetes burden and access to preventive care in the rural United States. Journal of Rural Health, 26(1), 3-11. http://dx.doi.org/10.1111/j.17480361.2009.00259.x

Liese, A. D., Weis, K. E., Pluto, D., Smith, E., \& Lawson, A. (2007). Food store types, availability, and cost of foods in a rural environment. Journal of the American Dietetic Association, 107(11), 1916-1923. http://dx.doi.org/10.1016/j.jada.2007.08.012

Lutfiyya, M., Chang, L. F., \& Lipsky, M. S. (2012). A cross-sectional study of US rural adults' consumption of fruits and vegetables: Do they consume at least five servings daily? BMC Public Health, 12(280).

Lutfiyya, M. N., Lipsky, M. S., Wisdom-Behounek, J., \& Inpanbutr-Martinkus, M. (2007). Is rural residency a risk factor for overweight and obesity for U.S. children? Obesity, 15(9), 2348-2356. http://dx.doi.org/10.1038/oby.2007.278

Muller, M., Tagtow, A., Roberts, S. L., \& MacDougall, E. (2009). Aligning food systems policies to advance public health. Journal of Hunger and Environmental Nutrition, 4(3-4), 225-240. http://dx.doi.org/10.1080/19320240903321193

O’Connell, M., Buchwald, D. S., \& Duncan, G. E. (2011). Food access and cost in American Indian communities in Washington State. Journal of the American Dietetic Association, 111(9), 1375-1379. http://dx.doi.org/10.1016/j.jada.2011.06.002

Pitts, S. B. J., Smith, T. W., Thayer, L. M., Drobka, S., Miller, C., Keyserling, T. C., \& Ammerman, A. S. (2013). Addressing rural health disparities through policy change in the stroke belt. Journal of Public Health Management and Practice. Advance online publication. http://dx.doi.org/10.1097/ PHH.0b013e3182893bbb

Sharkey, J. R., Dean, W. R., \& Johnson, C. M. (2012). Use of vendedores (mobile food vendors), pulgas (flea markets), and vecinos o amigos (neighbors or friends) as alternative sources of food for purchase among
Mexican-origin households in Texas border colonias. Journal of the Academy of Nutrition and Dietetics, 112(5), 705-710.

Sharkey, J. R., Dean, W. R., \& Nalty, C. (2012). Convenience stores and the marketing of foods and beverages through product assortment. American Journal of Preventive Medicine, 43 (3 Supplement 2), S109-S115. http://dx.doi.org/10.1016/j.amepre.2012.05.012

Sharkey, J. R., Dean, W. R., Nalty, C. C., \& Xu, J. (2013). Convenience stores are the key food environment influence on nutrients available from household food supplies in Texas border colonias. BMC Public Health, 13, 45. http://dx.doi.org/10.1186/1471-2458-13-45

Sharkey, J. R., Horel, S., Han, D., \& Huber, J. C. (2009). Association between neighborhood need and spatial access to food stores and fast food restaurants in neighborhoods of Colonias. International Journal of Health Geographics, 8(9). http://dx.doi.org/10.1186/1476-072X-8-9

Sharkey, J. R., Johnson, C. M., Dean, W. R., \& Horel, S. A. (2011). Focusing on fast food restaurants alone underestimates the relationship between neighborhood deprivation and exposure to fast food in a large rural area. Nutrition Journal, 10(10). http://dx.doi.org/10.1186/1475-2891-10-10

Smith, C., \& Morton, L. W. (2009). Rural food deserts: Low-income perspectives on food access in Minnesota and Iowa. Journal of Nutrition Education and Behavior, 41(3), 176-187. http://dx.doi.org/10.1016/i.jneb.2008.06.008

Story, M., Hamm, M. W., \& Wallinga, D. (2009). Food systems and public health: Linkages to achieve healthier diets and healthier communities. Journal of Hunger and Environmental Nutrition, 4(3-4), 219-224. http://dx.doi.org/10.1080/19320240903351463

Story, M., Kaphingst, K. M., Robinson-O’Brien, R., \& Glanz, K. (2008). Creating healthy food and eating environments: Policy and environmental approaches. Annual Review of Public Health, 29, 253-272. http://dx.doi.org/10.1146/annurev. publhealth.29.020907.090926

Ulmer, V. M., Rathert, A. R., \& Rose, D. (2012). Understanding policy enactment: The New Orleans Fresh Food Retailer Initiative. American Journal of Preventive Medicine, 43 (3 Supplement 2), S116-S122. http://dx.doi.org/10.1016/j.amepre.2012.05.011 
Valdez, Z., Dean, W. R., \& Sharkey, J. R.. (2012). Mobile and home-based vendors' contributions to the retail food environment in rural south Texas Mexicanorigin settlements. Appetite, 59(2), 212-217. http://dx.doi.org/10.1016/j.appet.2012.04.012

Van Hoesen, J., Bunkley, B., \& Currier, C. (2013). A GIS-based methodology toward refining the concept of rural food deserts: A case study from Rutland County, Vermont. Journal of Agriculture, Food Systems, and Community Development, 3(2), 61-76. http://dx.doi.org/10.5304/jafscd.2013.032.006
Wegener, J., \& Hanning, R. M. (2010). Concepts and measures of "alternative" retail food outlets: Considerations for facilitating access to healthy, local food. Journal of Hunger and Environmental Nutrition, 5(2), 158-173. http://dx.doi.org/10.1080/19320248.2010.487023

Yousefian, A., Leighton, A., Fox, K., \& Hartley, D. (2011). Understanding the rural food environment - Perspectives of low-income parents. Rural and Remote Health, 11(2), 1631. Retrieved from http://www.rrh.org.au 